\title{
IJIKMMENA \\ 2,2 \\ DRIVING CYCLES AS THE TOOL TO ASSESS TRAFFIC DEMAND MANAGEMENT (TDM) IN ABU DHABI CITY
}

\author{
Ahmed Al Zaidi' \\ Edinburgh Napier University, UK
}

\begin{abstract}
Purpose: This study uses driving cycle to investigate and assess traffic demand management (TDM) for a number of traffic corridors in Abu Dhabi. Driving cycle measurements have had many applications to date, including the evaluation of the driver's behaviour and the performance of vehicles in a number of applications, in particular, for fuel consumption estimation and emission predictions.

Design/methodology/approach: One TDM measures is considered; bus lanes. At each corridor, a hand-held GPS device was used to record speed, acceleration, deceleration and distances driven at 1 second intervals.

Findings: Bus lanes are not a sustainable policy in all cases. These data enabled the analysis of driving cycles for buses and private cars.

Originality/value: Use of the driving cycle analysis to assess and evaluate transport policies.
\end{abstract}

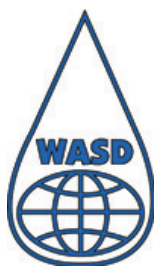

Keywords: Traffic Demand Management (TDM), Driving cycle, Bus lane, Performance box, Speed of motor vehicles, Linear Regression Analyses

Paper type: Research paper

International Journal of Innovation and Knowledge Management in Middle East \& North Africa Vol. 2 No. 2, 2013

${ }^{1}$ Ahmed Al Zaidi, Edinburgh Napier University, 10 Colinton Road, Edinburgh, UK, Email: 07017078@live.napier.ac.uk 


\section{INTRODUCTION}

The purpose of this report is to carry out an investigation of driving cycle from data collected on traffic passing along selected traffic corridors in Abu Dhabi. The development of representative driving cycles is a very important tool for an efficient assessment of transport policies, as can be seen from the extensive field of studies which have used them for this purpose (e.g. Saleh et al., 2009; Simanaitis, 1977; Kent et al., 1978; Kuhler and Karsten, 1978; Watson et al., 1982; Wang et al., 1985; Lyons et al., 1986; Andre et al., 1995; Tzeng and Chen, 1998; Chen et al., 2003; Booth et al., 2001; Shafiepour and Kamalan, 2005; Tsai et al., 2005; Hung et al., 2007). In this research, we utilise the principles of driving cycle analysis with the long term objective of assessing and monitoring impacts of traffic management policies.

\section{DRIVING CYCLES}

\section{Definition of driving cycle}

For the development of driving cycles, data collection was carried out using a GPS, a performance box and data logging equipment, while travelling on buses or driving an equipped car. Modelling the driving cycles requires the synthesis of a large amount of data collected from the field. In each case study, there were large numbers of test runs. Each test run comprised a series of major kinematic sequences (i.e. speed vs. time curve) which were divided into a number of minor kinematic sequences (also called micro-trips). These data (which were collected at 0.1 second time intervals), were exported to Excel software to calculate the assessment parameters. Data on speed, time, distance, acceleration, deceleration, idling and cruising were analysed for each of the corridors. A number of assessment parameters were estimated, including percentage of time spent in acceleration, percentage of time spent in deceleration, percentage of time spent idling and percentage of time spent cruising. These assessment parameters were then used for each of the selected corridors. The following list shows the assessment parameters used in this study:

1. Average speed of the entire driving cycle $(v)$;

2. Average acceleration $(a)$;

3. Average deceleration $(d)$;

4. Average trip duration $(t)$;
Driving cycles to assess Traffic Demand Management in Abu Dhabi city 
IJIKMMENA

2,2

159
5. Percentage time spent in driving modes for idling $\left(P_{\mathrm{i}}\right)$;

6. Percentage time spent in driving modes for acceleration $\left(P_{\mathrm{a}}\right)$;

7. Percentage time spent in driving modes for cruising $\left(P_{c}\right)$;

8. Percentage time spent in driving modes for deceleration $\left(P_{d}\right)$;

9. Root mean square acceleration $\left(a_{\mathrm{rms}}\right)$; and

10. Standard deviation $\left(S_{d}\right)$

The parameters used are defined as follows:

Average acceleration: The average acceleration of all acceleration phases.

Average deceleration: The average deceleration of all deceleration phases.

Cruising mode: $\quad$ Portions of driving having absolute incremental speed changes of less than or equal to $0.1 \mathrm{~m} / \mathrm{s}-2$.

Acceleration mode: Proportions of driving having positive incremental speed changes of more than $0.1 \mathrm{~m} / \mathrm{s}-2$.

Deceleration mode: Portions of driving having negative incremental speed changes of more than $0.1 \mathrm{~m} / \mathrm{s}-2$.

The data analysis for this report was carried out using the performance box analysis programme and Microsoft Excel. After the collected data set was opened in the performance box programme, it was edited to remove the time spent stationary while waiting for a car to enter the test area. After the data were edited, the remaining data were exported to Excel and saved as an Excel file.

\section{DERIVATION OF DRIVING CYCLE}

The driving cycles were derived by examining the statistical resemblance of the seven defined parameters. These assessment parameters were also used to derive driving cycles by several researchers (Tzeng, 1998; Hung 2007; Tsai, 2005; Andre, 2004; Saleh et al., 2009). These parameters are the most appropriate for assessing and defining the driving cycle in the case of bus lane assessment and for the assessment of traffic calming measures. This is because the percentage of time spent in each of the driving cycles is a good reflection of the efficiency of the policies implemented. 
The overall mean value of each of the seven defined parameters, standard deviations (SD) and coefficients of variations (COV) of those assessment parameters were estimated for each of the test runs for each of the corridors. The COV values were calculated to show the variations in the performance of the test runs for the corridors.

A further refining of the driving cycle was done by calculating the absolute sums of the relative error $(\mathrm{Sj})$ then selecting the driving cycle with the minimum value of $\mathrm{Sj}$. The relative error value for each of the parameters $\left(\Delta_{k}\right)$ is:

$$
\Delta_{k}=\frac{\left(\bar{p}-p_{j}\right)}{p_{j}} * 100 \quad \text { eq. } 5.1
$$

Where $\mathrm{k}$ is an assessment parameter ( $\mathrm{k}$ varies from 1 to 7 ) and $\Delta_{\mathrm{k}}$ is the value of the relative error for parameter $\mathrm{k}, \bar{P}$ is overall mean value of parameters. $P_{i j}$ is a parameter with a value of a run $i$ (between 1 and number of runs) and corridor category $\mathrm{j}$. The absolute sum of the relative errors $(\mathrm{S} j)$ was calculated for each corridor category type by summing up the individual relative error for a given corridor (Eq. 5.2):

$$
S_{j}=\sum_{k=1}^{7} \Delta k \quad \text { eq } 5.1
$$

The minimum value of the sum of absolute error (\%) $\mathrm{Sj}$ for the corridors in each category was then identified and the corridor driving cycle was selected as a representative driving cycle for that category. For example, for the mixed traffic corridors in Abu Dhabi, the inbound and outbound traffic corridors were analysed and compared and the driving cycle with the minimum (\%) Sj was selected to be the representative driving cycle for the bus lane corridors.

\section{CASE STUDY}

Two traffic corridors in Abu Dhabi (two corridors with mixed traffic, i.e., all traffic share all lanes on the corridor) have been selected which are: Airport Road and Electra Road in Abu Dhabi.

Airport Road (from Al Falah Street with Airport Road junction to Mohamed Bin Khalifa Street with Airport Road junction), has no bus lane. It is the most important road in Abu Dhabi city. The measurements of driving cycle for buses and cars on Airport Road started from Al Falah Street with Airport Road junction to Mohamed Bin Khalifa
Driving cycles to assess Traffic Demand Management in Abu Dhabi city

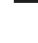


IJIKMMENA 2,2

Street with Airport Road junction. The Airport Road corridor is a dual carriageway; it has four lanes in both directions for all type of vehicles, and there is no dedicated bus lane. The length of the investigated corridor is approximately 1.0 mile. The corridor is very busy during peak hours, because the investigated part has four signalised junctions (Figure 1).

Electra Road (from Airport Road with Electra Street junction to Al Salam Street with Electra Street junction), has no bus lane. This street runs parallel to Hamdan Street and is situated in the heart of Abu Dhabi city, with many commercial shops on both sides. The measurements of driving cycle for bus and car on Electra Street started from Airport Road with Electra Street junction to Al Salam Street with Electra Street junction. The Electra Street corridor is a dual carriageway; it has four lanes in both directions for all type of vehicles, and there is no dedicated bus lane. The length of the investigated corridor is approximately 1.0 mile. The corridor is very busy during peak hours, because the investigated part has four signalised junctions (Figure 2).

\section{a. Data collection for developing driving cycle for cars and buses at Airport Road}

The data were collected as part of a $\mathrm{PhD}$ study by driving the instrumented car and collecting data via performance box at selected locations in Abu

Figure I. The Airport Road Corridor






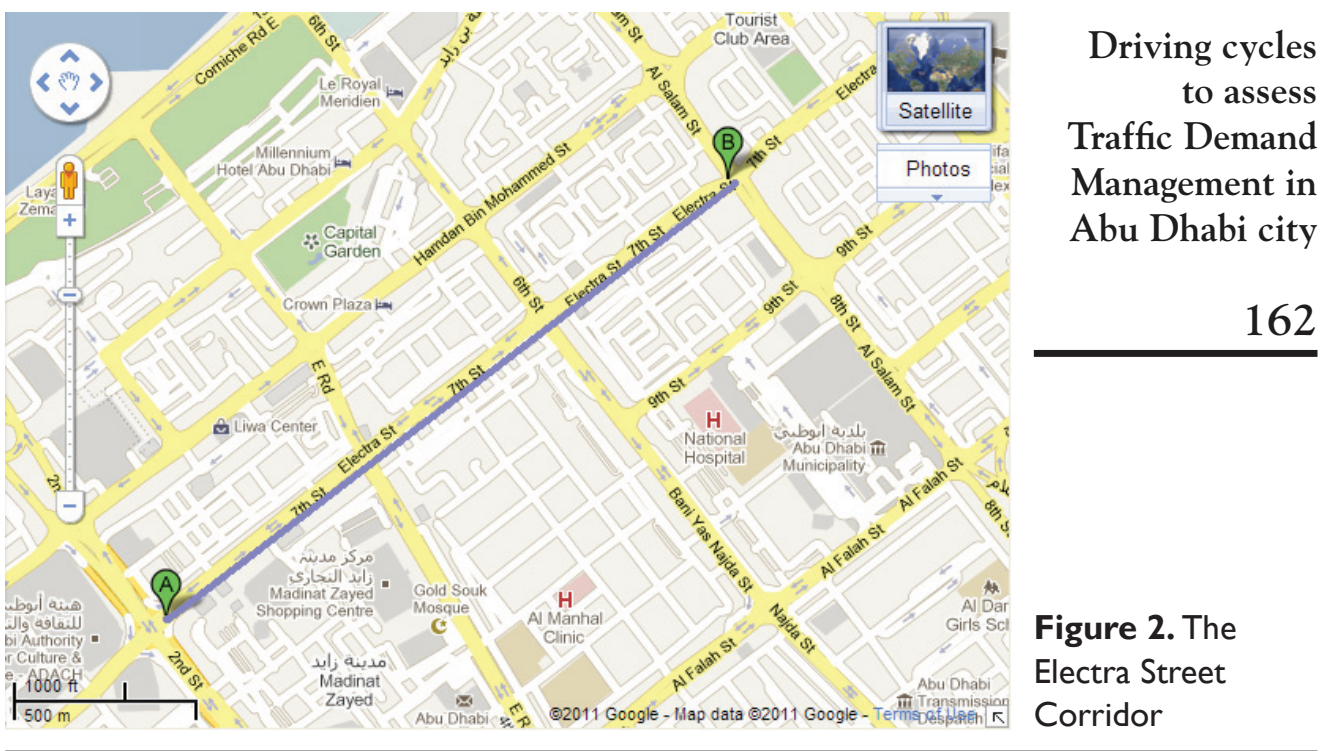

Dhabi city. As at present, there are no bus lanes in Abu Dhabi; however, that might change in the future. The data for public transport were collected again by the author by riding on public transport carrying a hand-held performance box. Here too, detailed information about the target factors affecting the driving cycle, including engine size, engine type and year, fuel consumption and route details were collected to develop and compare the driving cycles for cars and buses as accurately as possible.

The data, as mentioned in the previous section, were collected from Airport Road in order to develop the driving cycles for cars and buses for Abu Dhabi city. The data were collected for both peak hour and normal hours and in both directions of the route. The peak hour in Abu Dhabi is between 6.30 and 7.30 am. Nonetheless, it was also assumed that there would be no significant day-to-day variations in the traffic conditions on weekdays. As mentioned earlier, this study only focuses on the driving cycles for weekdays; hence only data for weekdays were collected. Each day was covered by the morning peak (6.30 - 7.30 a.m.) and non-peak hour of the afternoon (11.00 a.m. 12.00 p.m.) which takes account of the daily variations. Differences in driving patterns were also expected due to the difference in activities at different periods. 
IJIKMMENA

2,2

\section{b. Data collection for developing driving cycle for cars and buses at Electra Road}

The data were collected at Electra Road which is in the heart of Abu Dhabi city with many commercial shops on both sides. The Electra Street corridor is a dual carriageway; it has four lanes in both directions for all type of vehicles, and there is no dedicated bus lane. The length of the investigated corridor is approximately 1.0 mile. The corridor is very busy during peak hours, because the investigated part has four signalised junctions. The data were collected primarily by the author by travelling on public transport and collecting data via performance box. Detailed information about the target factors affecting the driving cycle, including bus characteristics, number of passengers and details about the routes were collected in order to estimate candidate driving cycles as accurately as possible. The data were collected for both peak hour and normal hours and in both directions of the route. Collection was also based on the assumption that there would be no significant day-to-day variations, but that there would be differences between weekdays and weekends, and drivers. Each day was covered by the morning peak (6.30 - 7.30 a.m.) and non-peak hour of the afternoon (11.00 a.m. - 12.00 p.m.) which takes account of the daily variations.

After logging the data, the entered speed, acceleration, and decelerations were plotted against time data and were inspected visually for any abnormal characteristics. Here too, the Performance Box software tool was used to repair the file by clicking on the Tools menu and choosing the File Repair option (Manual for Performance Box, 2007). The data acquisition system was followed as described in the previous section; it constitutes the database in which the types of vehicle, road types, time of travel and operating conditions were stored. It is also assumed that the data collected via car and bus is representative of the "typical traffic stream" of Abu Dhabi, hence the car-following technique was used. In addition, in the case of buses, the drivers traversed their usual journeys, so their driving behaviour was assumed to be representative. The testing duration varied from $06.30-7.30$ (RHM), and $11.00-12.00$ (nonrush hours, NRH). Test runs were done ten times for each route and in each direction; a total number of 160 runs were finalised for analysis. Tables $4-7$ shows the breakdown of test runs over each of the routes during different hours. 


\section{RESULTS AND DISCUSSION}

\section{c. Analysis of the performance of buses on the Airport Road in Abu Dhabi}

Table 1 presents the data to be analysed for the busses travelling on the Airport Road within Abu Dhabi. These statistics have been extracted from the whole data set and were selected because they represent the data collected with the lowest relative errors. These data show that there is a significant difference in the average time taken to complete the route by the busses for the given time periods. This difference can be slightly mitigated when we adjust the average time to account for the difference in the length of the corridor under examination in the two situations. Given that in the off-peak time period, the corridor is in fact shortened by 83.419 meters, if we adjust the average time taken to account for this discrepancy, we see that the duration adjusts to 453.12 seconds. This is still, however, a significant difference in time taken to complete the same route. This clearly indicates to us that there are extremely different conditions present in the two time periods.

Given that the percentages of time spent in acceleration are virtually identical in the two time periods, along with the fact that the percentage of time spent decelerating is $4.9 \%$ lower in the off-peak time, we can infer that the driver is capable of adopting a more aggressive driving style. This would lead us to believe that there is much less congestion on the route as the driver feels safe in the adoption of this driving style.

It can also be seen that the idling times are $4.4 \%$ higher in peak time. This indicates that the buses were required to spend a much greater time stationary throughout the corridor in this time period. The reasons for this may be that due to increased traffic flows, there are larger queues forming at signalised junctions. These higher delays may also be due to increased passenger numbers using the buses on the corridor at this time,

\begin{tabular}{|c|c|c|c|c|c|c|c|c|}
\hline Route & Time & $\begin{array}{c}\text { Average } \\
\text { Time } \\
(\mathrm{Sec})\end{array}$ & $\begin{array}{l}\text { Average } \\
\text { Speed } \\
(\mathrm{Km} / \mathrm{h})\end{array}$ & $\begin{array}{l}\text { Average } \\
\text { Length } \\
\text { (Metre) }\end{array}$ & $\begin{array}{c}\% \\
\text { Acc }\end{array}$ & $\begin{array}{c}\% \\
\text { Dec }\end{array}$ & $\begin{array}{c}\% \\
\text { Idling }\end{array}$ & $\begin{array}{c}\% \\
\text { Cruising }\end{array}$ \\
\hline \multirow{2}{*}{$\begin{array}{l}\text { Airport } \\
\text { Road }\end{array}$} & $\begin{array}{c}6.30 . \\
7.30 \mathrm{am}\end{array}$ & 544.9 & 15.61 & 2331.912 & 0.186 & 0.173 & 0.302 & 0.335 \\
\hline & $\begin{array}{l}11.00 \\
12.00 \mathrm{am}\end{array}$ & 437.42 & 19.127 & 2248.493 & 0.187 & 0.124 & 0.258 & 0.427 \\
\hline
\end{tabular}

$$
\text { (nceased pasenger numbers using the buses on the cotidor at this time, }
$$

Driving cycles to assess Traffic Demand Management in Abu Dhabi city 
IJIKMMENA

2,2

165

which would require a greater duration spent at each stop to allow for the alighting of this greater volume of people.

It is also clear that a much freer movement of vehicles is allowed during the off-peak time period due to the fact that there is an increase of $9.2 \%$ in the journey time in the cruising phase when compared to the peak time. This would also indicate that the buses are able to move much more easily without obstruction from other vehicles during this period.

\section{d. Analysis of the performance of buses on the Electra Road in Abu Dhabi}

Table 2 presents the data to be analysed for buses travelling on the Electra Road within Abu Dhabi. These statistics have been extracted from the whole data set and have been selected because they represent the data collected with the lowest average relative errors.

As in previous situations, the lowest relative error was presented on the corridor with readings taken when the vehicle was travelling in the same direction. However in this situation, the lowest relative errors are presented in opposing directions. It has therefore been deemed prudent to select those observations which provide the lowest average relative error, so as to present a comparison of two sets of numbers that were calculated on the same stretch of road operating in the same direction. This has been deemed necessary in this situation because there is an extra bus stop on this route in the outward direction, which could possibly lead to a discrepancy in the interpretation of the results.

In this scenario, we can see that there is a large variation in the average times taken to complete the corridor; however this can be ignored due to the fact that there is a significant difference in the length of the corridor being examined in the two time periods. The average

\begin{tabular}{|c|c|c|c|c|c|c|c|c|c|}
\hline Table 2. Summary & Route & Time & $\begin{array}{l}\text { Average } \\
\text { Time } \\
(\mathrm{Sec})\end{array}$ & $\begin{array}{l}\text { Average } \\
\text { Speed } \\
(\mathrm{Km} / \mathrm{h})\end{array}$ & $\begin{array}{l}\text { Average } \\
\text { Length } \\
\text { (Metre) }\end{array}$ & $\begin{array}{c}\% \\
\text { Acc }\end{array}$ & $\begin{array}{c}\% \\
\text { Dec }\end{array}$ & $\begin{array}{c}\% \\
\text { Idling }\end{array}$ & $\begin{array}{c}\% \\
\text { Cruising }\end{array}$ \\
\hline $\begin{array}{l}\text { driving cycle } \\
\text { parameters for }\end{array}$ & Electr: & $\begin{array}{c}6.30 . \\
7.30 \mathrm{am}\end{array}$ & 323.077 & 20.502 & 1819.247 & 0.179 & 0.154 & 0.196 & 0.467 \\
\hline $\begin{array}{l}\text { Electra Road,Abu } \\
\text { Dhabi }\end{array}$ & Road & $\begin{array}{c}11.00 \\
12.00 \mathrm{am}\end{array}$ & 291.47 & 20.636 & 1649.049 & 0.195 & 0.164 & 0.199 & 0.438 \\
\hline
\end{tabular}


speeds are vertically identical, so we can hypothesise that the overall traffic management methods adopted on this route must be very effective as there is an ability to maintain near uniform average speeds on the route through both peak and off-peak traffic flow situations.

As we examine the driving style adopted by the drivers further based on the acceleration and deceleration statistics available, we can see that a greater percentage of the journey is spent carrying out these operations in the off-peak time period. This indicates to us that the driver has adopted a much more relaxed driving style. This may be based on a number of factors; however, it may be possible to infer that it is due to an increase in overall traffic volume on the route during this period and therefore the driver is not capable of accelerating as freely without the risk of obstruction from other vehicles. As the overall idling time on this route only varies by $0.3 \%$, we may infer that there are a near constant number of passengers using this route, as there is no need for the buses to remain stationary for long periods to allow for the boarding and disembarking of these passengers. The near uniformity of these figures also further indicates that there is an extremely efficient traffic management system in place along this route, as no variations in the length of time spent queuing at signalised junctions are occurring.

Due to the presence of an increase of $2.9 \%$ in the overall journey time spent cruising in the peak traffic time period, we infer that there is a generally freer movement of buses taking place, and this may be attributed to an overall reduction in vehicle volumes along the corridor at this time.

\section{e. Analysis of the performance of cars on the Airport Road in Abu Dhabi}

Table 3 presents the data to be analysed for cars travelling on the Airport Road within Abu Dhabi. These statistics have been extracted from the

\begin{tabular}{|c|c|c|c|c|c|c|c|c|c|}
\hline Route & Time & $\begin{array}{c}\text { Average } \\
\text { Time } \\
(\mathrm{Sec})\end{array}$ & $\begin{array}{c}\text { Average } \\
\text { Speed } \\
(\mathrm{Km} / \mathrm{h})\end{array}$ & $\begin{array}{l}\text { Average } \\
\text { Length } \\
\text { (Metre) }\end{array}$ & $\begin{array}{c}\% \\
\text { Acc }\end{array}$ & $\begin{array}{c}\% \\
\text { Dec }\end{array}$ & $\begin{array}{c}\% \\
\text { Idling }\end{array}$ & $\begin{array}{c}\% \\
\text { Cruising }\end{array}$ & \multirow{3}{*}{$\begin{array}{l}\text { Table 3. Summary } \\
\text { statistics of car } \\
\text { driving cycle } \\
\text { parameters for } \\
\text { Airport Road, Abu } \\
\text { Dhabi }\end{array}$} \\
\hline \multirow{2}{*}{$\begin{array}{l}\text { Airport } \\
\text { Road }\end{array}$} & $\begin{array}{c}6.30 . \\
7.30 \mathrm{am}\end{array}$ & 252.64 & 35.628 & 2387.998 & 0.206 & 0.175 & 0.143 & 0.472 & \\
\hline & $\begin{array}{c}11.00 \\
12.00 \mathrm{am}\end{array}$ & 188.35 & 45.609 & 2364.854 & 0.203 & 0.159 & 0.074 & 0.56 & \\
\hline
\end{tabular}

Driving cycles to assess Traffic Demand Management in Abu Dhabi city 
IJIKMMENA

2,2

whole data set and have been selected because they represent the data collected with the lowest relative errors. These results show that there is a significant difference between the speeds achievable by car users on this route on off-peak times as opposed to peak times. We can see that there is an ability to achieve an increase of $9.98 \mathrm{~km} / \mathrm{hr}$ during the offpeak time period, which results in a decrease of 64.29 seconds in the average journey time. From the data available regarding the driving style adopted, we can see that the total percentage taken for acceleration and deceleration for the two time periods varies by $1.9 \%$. From this piece of information we can conclude that there is a much more aggressive driving style adopted by car users during the off-peak time. A much higher speed is being achieved before the car returns to a stationary position, taking less time than in the peak period. The reasoning for this may be safely assumed to be that there are significantly less traffic volumes using the route during off-peak times, thus allowing for much more rapid unhindered acceleration and deceleration.

This is also reflected in the data provided for the amount of time spent in the idling and cruising phases for the two time periods. Given that $6.9 \%$ more of the journey time is spent idling in the peak time period when compared to the off-peak time period, we can assume that there are significantly larger queues developing at the signalised junctions in place along the route. This creation of queues and increase in idling time has a knock-on effect in reducing the percentage of the journey spent in the cruising phase, and thus increases the overall journey time.

\section{f. Analysis of the performance of cars on the Electra Road in Abu Dhabi}

Table 4 presents the data to be analysed for the cars travelling on the Electra Road within Abu Dhabi. These statistics have been extracted from the whole data set and have been selected because they represent

\begin{tabular}{|c|c|c|c|c|c|c|c|c|c|}
\hline Table 4. Summary & Route & Time & $\begin{array}{c}\text { Average } \\
\text { Time } \\
(\mathrm{Sec})\end{array}$ & $\begin{array}{c}\text { Average } \\
\text { Speed } \\
(\mathrm{Km} / \mathrm{h})\end{array}$ & $\begin{array}{l}\text { Average } \\
\text { Length } \\
\text { (Metre) }\end{array}$ & $\begin{array}{c}\% \\
\text { Acc }\end{array}$ & $\begin{array}{c}\% \\
\text { Dec }\end{array}$ & $\begin{array}{c}\% \\
\text { Idling }\end{array}$ & $\begin{array}{c}\% \\
\text { Cruising }\end{array}$ \\
\hline $\begin{array}{l}\text { dratistics of car } \\
\text { parameters for }\end{array}$ & Electra & $\begin{array}{c}6.30 . \\
7.30 \mathrm{am}\end{array}$ & 209.69 & 30.552 & 1762.837 & 0.187 & 0.112 & 0.245 & 0.452 \\
\hline $\begin{array}{l}\text { Electra Road, Abu } \\
\text { Dhabi }\end{array}$ & Road & $\begin{array}{c}11.00 \\
12.00 \mathrm{am}\end{array}$ & 203.033 & 33.459 & 1789.443 & 0.205 & 0.116 & 0.227 & 0.448 \\
\hline
\end{tabular}


the data collected with the lowest relative errors. These results show that there is only a small variance in the average time taken to complete the route in question, with only an increase of $2.9 \mathrm{~km} / \mathrm{hr}$ average speed over the course of the corridor. This indicates that a very small variation in the overall traffic volume is taking place along this route between the two time periods. Should higher traffic volumes be present in one or other of the time periods, we would expect to see a significant increase in the journey time along with an overall reduction in the average speed, both due to the increased congestion taking place. There may be alterations taking place in the overall traffic volume, but these results suggest that the road network that has been developed here is sufficient to deal with the variations in volume taking place without adversely effecting overall journey time for any of the car users throughout the day.

The $2.2 \%$ increase in the overall percentage of journey time spent in acceleration and deceleration suggests that there is slightly less traffic volume during the off-peak time, as there is an allowance for a greater duration of acceleration along with a higher overall average speed.

This is also reflected in the fact that $1.8 \%$ more of the journey is spent in the idling phase in the early morning peak time slot when compared to the afternoon off-peak time. However, the presence of a slightly higher average cruising percentage of $45.2 \%$ in the peak time when compared to the $44.8 \%$ of the off-peak time would lead us to a contrary belief.

It is clear due to the minimal variation in all of these statistics, however, that there is no significant change in the overall traffic volumes on this route between the two time periods in question, and if there is a slightly heavier traffic flow, it will occur in the early morning peak time.

\section{g. Analysis of the performance of cars and busses on the Airport Road in Abu Dhabi}

Table 5 presents the data to be analysed for the busses and cars travelling on the Airport Road within Abu Dhabi. These statistics have been extracted from Table 5 and have been selected because they represent the data collected with the lowest relative errors. These results show that there is a significant difference in journey times and average speeds achieved by the buses and cars on this corridor. However, this can be attributed to the fact that the route under examination is a dual carriageway, where there will
Driving cycles to assess

Traffic Demand Management in Abu Dhabi city

(n)


IJIKMMENA

2,2

169

be minimal disruption to car users when buses stop. This is clearly reflected in the data provided for the percentage of time spent in the idling phase. In both situations, this percentage is significantly higher for buses, which may be attributed to their need to make six extra stops along the route than the cars are required to make. The overall acceleration and deceleration percentage times only vary by $7.3 \%$ over the entire course of the study on this route, which indicates a very uniform flow of traffic occurring throughout. The main reason for the slightly higher acceleration and deceleration rates of the cars is because they are achieving a significantly higher average speed than the buses, which will require a longer time to reach these speeds, and in turn, a longer time to reduce speed. We can also see that the cruising rates for buses are significantly lower than those of the cars throughout the two time periods; however this is clearly dependant on the idling rates, and as the buses are required to remain stationary for a greater period of time, the cruising rate will in turn decrease.

\section{h. Analysis of the performance of cars and busses on the Electra Road in Abu Dhabi}

Table 6 presents the data to be analysed for the buses and cars travelling on the Electra Road within Abu Dhabi. These statistics have been extracted from Table 5 and have been selected because they represent the data collected with the lowest relative errors.

From the above data we can see that there is a rather large variance in the average time spent on the journey by the different modes of transport. This is clearly associated with the fact that much lower average speeds are being achieved by the buses (on average $11.44 \mathrm{~km} / \mathrm{hr}$ ).

These overall speeds do not represent any significant variation in the overall driving style present on the route, however. This can be inferred

\footnotetext{
Table 5. Summary statistics of car and bus driving cycle parameters for Airport Road, Abu Dhabi
}

\begin{tabular}{|c|c|c|c|c|c|c|c|c|c|}
\hline Route & Time & Mode & $\begin{array}{l}\text { Average } \\
\text { Time } \\
(\mathrm{Sec})\end{array}$ & $\begin{array}{c}\text { Average } \\
\text { Speed } \\
(\mathrm{Km} / \mathrm{h})\end{array}$ & $\begin{array}{l}\text { Average } \\
\text { Length } \\
\text { (Metre) }\end{array}$ & $\begin{array}{c}\% \\
\text { Acc }\end{array}$ & $\begin{array}{c}\% \\
\text { Dec }\end{array}$ & $\begin{array}{c}\% \\
\text { Idling }\end{array}$ & $\begin{array}{c}\% \\
\text { Cruising }\end{array}$ \\
\hline \multirow{4}{*}{$\begin{array}{l}\text { Airport } \\
\text { Road }\end{array}$} & \multirow{2}{*}{$\begin{array}{c}6.30 . \\
7.30 \mathrm{am}\end{array}$} & Bus & 544.9 & 15.61 & 2331.912 & 0.186 & 0.173 & 0.302 & 0.335 \\
\hline & & Car & 252.64 & 35.628 & 2387.998 & 0.206 & 0.175 & 0.143 & 0.472 \\
\hline & \multirow{2}{*}{$\begin{array}{c}11.00 \\
12.00 \mathrm{am}\end{array}$} & Bus & 437.42 & 19.127 & 2248.493 & 0.187 & 0.124 & 0.258 & 0.427 \\
\hline & & Car & 188.35 & 45.609 & 2364.854 & 0.203 & 0.159 & 0.074 & 0.56 \\
\hline
\end{tabular}


from the fact that there is only a $7.2 \%$ variation in the overall acceleration and deceleration statistics. Given that there is a requirement of the cars to achieve higher speeds on average, this is a minimal variation in overall driving style over the duration of the route being examined.

One surprising statistic is that in total, the cars spend on average $7.7 \%$ more of the journey time idling compared to the buses. This is an even more interesting figure given that the buses are required to service five stops on this inward journey, whereas cars are not required to become stationary at these locations. This information suggests that the stops must be located close to signalised junctions, as this would help to reduce the impact these stops will have on this data field. The fact that this idling percentage figure for the cars is greater, together with the fact that there is a minimal variation in the overall cruising percentages experienced along the route suggests that the traffic flows on this route are extremely uniform and are probably heavily controlled by the signalised junctions. It is clear that the higher average speeds are being produced by the cars because of their ability to carry out acceleration at a much greater rate than the buses, and this is the main reason that a reduced journey time is presented.

\section{CONCLUSIONS}

We have seen that the analysis of driving cycles is a very useful tool in the assessment of the effectiveness of transport measures and policies when they are installed on an existing route. The analysis of driving cycle data taken before and after the installation of the measures allows us to gain an insight into the attitude of the driver using the route during both situations. This allows us to determine if the installation has in fact resulted in the establishment of an overall more uniform and controlled

\begin{tabular}{|c|c|c|c|c|c|c|c|c|c|c|}
\hline Route & Time & Mode & $\begin{array}{l}\text { Average } \\
\text { Time } \\
(\mathrm{Sec})\end{array}$ & $\begin{array}{c}\text { Average } \\
\text { Speed } \\
(\mathrm{Km} / \mathrm{h})\end{array}$ & $\begin{array}{l}\text { Average } \\
\text { Length } \\
\text { (Metre) }\end{array}$ & $\begin{array}{c}\% \\
\text { Acc }\end{array}$ & $\begin{array}{c}\% \\
\text { Dec }\end{array}$ & $\begin{array}{c}\% \\
\text { Idling }\end{array}$ & $\begin{array}{c}\% \\
\text { Cruising }\end{array}$ & \\
\hline \multirow{4}{*}{$\begin{array}{l}\text { Electra } \\
\text { Road }\end{array}$} & \multirow{2}{*}{$\begin{array}{c}6.30 \\
7.30 \mathrm{am}\end{array}$} & Bus & 323.077 & 20.502 & 1819.247 & 0.179 & 0.154 & 0.196 & 0.467 & \multirow{4}{*}{$\begin{array}{l}\text { Table 6. Summary } \\
\text { statistics of car and } \\
\text { bus driving cycle } \\
\text { parameters for } \\
\text { Electra Road, Abu } \\
\text { Dhabi }\end{array}$} \\
\hline & & Car & 209.69 & 30.552 & 1762.837 & 0.187 & 0.112 & 0.245 & 0.452 & \\
\hline & \multirow{2}{*}{$\begin{array}{c}11.00 \\
12.00 \mathrm{am}\end{array}$} & Bus & 291.47 & 20.636 & 1649.049 & 0.195 & 0.164 & 0.199 & 0.438 & \\
\hline & & Car & 203.033 & 33.459 & 1789.443 & 0.205 & 0.116 & 0.227 & 0.448 & \\
\hline
\end{tabular}

Driving cycles to assess Traffic Demand Management in Abu Dhabi city

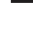


IJIKMMENA

2,2

driving style. This is represented in an overall increase or decrease in the percentage times of the journey spent in the various driving phases. If a traffic calming system, for example, is assessed, it is important to investigate, analyse and assess the driving cycle of this policy before implementation. If, on the other hand, there is some form of traffic light system put in place, we should expect to see an increase in idling, deceleration and acceleration taking place, with a corresponding decrease in cruising. Further research in this area is also highly recommended.

\section{REFERENCES}

Andre, M. (2004), "The ARTEMIS European driving cycles for measuring car pollutant emissions", Science of the Total Environment, Vols. 334 and 335, pp. 73-84.

Andre, M., Hickman, J., Hassel, D., and Joumard, R. (Eds.), (1995), "Driving cycles for emission measurements under European conditions", in: Global Emission Experiences: Processes, Measurements and Substrates. Society of Automotive Engineers (SAE), Warrendale, SP-1094. pp. 193-205.

Booth, A.E., Munner, T., and Kirby, H.R. (2001), "The measurement of vehicular driving cycle within city of Edinburgh", Transportation Research Part D, Vol. 6, pp. 209-220.

Chen, K.S., Wang, W.C., Chen, H.M., Lin, C.F., Hsu, H.C., Kao J.H. and Hu, M.T. (2003), "Motorcycle emissions and fuel consumption in urban and rural driving conditions", Science of the Total Environment, Vol. 312, pp. 113-122.

Hung, W.T., Tong, H.Y., Lee, C.P., Ha, K. and Pao, L.Y. (2007), "Development of a practical driving cycle construction methodology: A case study in Hong Kong", Transportation Research-D, Vol. 12, pp. $115-128$.

Kent, J.H., Allen, G.H. and Rule, G. (1978), "A driving cycle for Sydney”, Transportation Research, Vol. 12 No. 3, pp. 147-152.

Kuhler, M. and Karsten, D. (1978), "Improved driving cycle for testing automotive exhaust emissions", Societies Automotive Engineer, 780650, Warrendale.

Lyons, T.J., Kenworthy, J.R., Austin, P.I. and Newman, P.W.G. (1986), "The development of a driving cycle for fuel consumption and 
emissions evaluation", Transportation Research-A, Vol. 20 No. 6, pp. 447-462.

Saleh, W., Kumar, R. and Kirby, H. (2009), "Real world driving cycle for motorcycles in Edinburgh", Transportation Research-D, Vol. 14 No. 5 , pp. 326-333.

Simanaitis, D.J. (1977), "Emission test cycles around the world", Automotive Engineering, Vol. 85, pp. 34-43.

Shafiepour, M. and Kamalanh, H. (2005), "Air Quality Deterioration in Tehran Due To Motorcycles", Iran Journal of Environment and Health Science Engineering, Vol. 2 No. 3, pp. 145-152.

Tsai, J.H., Chiang, H.L., Chun, H.Y., Penga, B.J. and Hung, R.F. (2005), "Development of a local real world driving cycle for motorcycles for emission factor measurements", Atmospheric Environment, Vol. 39, pp. 6631-6641.

Tzeng, G.H. and Chen, J.J. (1998), "Developing a Taipei motorcycle driving cycle for emissions and fuel economy", Transportation Research-D, Vol .3, pp. 19-27.

Wang, C.S., Huang, Q.D., Ling, R.S. and Zhang, Y.T. (1985), Measurement of passenger car operation in Beijing pertinent to exhaust and fuel economy, SAE Paper, 852242.

Watson, H.C., Milkins, E.E. and Braunsteins, J. (1982), "The development of the Melbourne peak cycle", in: Joint SAE-A/ARRB Second Conference on Traffic, Energy and Emission. 82148, Melbourne.

\section{ABOUT THE AUTHOR}

Ahmed Al Zaidi worked as police officer in Abu Dhabi Police at Strategic Department and Police Traffic Department for almost nine years. Currently he is completing his $\mathrm{PhD}$ in the School of Engineering and the Built Environment at Edinburgh Napier University, UK. He holds a Bachelor's Degree in Law and Police Sciences from Abu Dhabi Police College in UAE, Abu Dhabi and an MSc Degree on Transport Planning and Policy from Newcastle University, UK. His most recent publication was presented at the 7th International Conference of the World Association for Sustainable Development (WASD), Bahrain. The paper focused on Investigation of Urban Driving Cycle and Relevant Geometric Factors in Abu Dhabi.
Driving cycles to assess Traffic Demand Management in Abu Dhabi city 